\title{
ORIENTATIONAL PHASE TRANSITIONS IN ALLOYS
}

\author{
Marie-Louise Saboungi, Gerald K. Johnson and David Long Price \\ Argonne National Laboratory
Argonne, IL 60439-4837 \\ Argonne National Laboratory
Argonne, IL 60439-4837
}

$6 \cdot 4=920(-2) c^{2}-3$

ANL/MSD/CP-77632

DE93 001702

\begin{abstract}
The submited manuscript has been authored by a contractor of the U.S. Government under contract No. W-31-109-ENG-38. Accordingly, the U.S. Government retains a nonoxclusive, royatiy-tree ticense to publish or reproduce the puthinhed lom of this contribution, or allow others to do so, for U.S. Government purposes.
\end{abstract}

22 September 1992

\section{DISCLAIMER}

This report was prepared as an account of work sponsored by an agency of the United States Government. Neither the United States Government nor any agency thereof, nor any of their employees, makes any warranty, express or implied, or assumes any legal liability or responsibility for the accuracy, completeness, or usefulness of any information, apparatus, product, or process disclosed, or represents that its use would not infringe privately owned rights. Reference herein to any specific commercial product, process, or service by trade name, trademark, manufacturer, or otherwise dnes not necessarily constitute or imply its endorsement, recommendation, or favoring by the United States Government or any agency thereof. The views and opinions of authors expressed herein do not necessarily state or reflect those of the United States Government or any agency thereof.

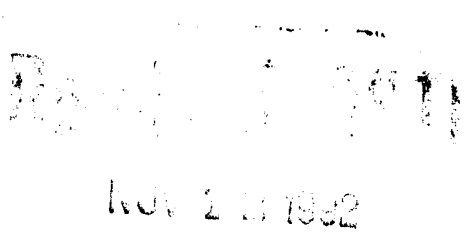

To be published in the Proceedings of the NATO Advanced Study Institute on "Statics and Dyramics of Alloy Phase Transformations", Rhodes, Greece, June 22, July 3, 1992. Ed. A. Gonis and P. Turchi, Plenum, NY

This work is supported by the U.S. Department of Energy, Basic Energy Sciences, Materials Sciences, under contract No. W-31-109-ENG-38. 
ORIENTATIONAL PHASE TRANSITIONS IN ALLOYS

Marie-Louise Saboungi, Gerald K. Johnson and David Long Price

Argonne National Laboratory

Argonne, IL 60439

\section{INTRODUCTION}

The submitted manuxcript has been suthored by a contractor of the U.S. Government under contrect No. W-31.109ENG-38. Accordingly, the U.S. Government retains nonexclusive, royatty-free license to publish or reproduce the published form of this conterion, or allow others to do $s$, for U. S. Government purposes.

Complex intermetallic phases such as Frank Kasper, Laves and Zintl compounds have local structural units of high symmetry, often tetrahedral or icosahedral. Such systems can undergo both translational and orientational disorder, leading to a variety of possible phases, shown schematically in Figure 1. They tend to have a semiconducting electronic structure, characterized by a small gap (or pseudo-gap) at the Fermi surface and leading to relatively high resistivities $\left(10^{3}-10^{4} \mathrm{~m} \Omega \mathrm{cm}\right)$.

Quasicrystals, a novel kind of matter with long-range orientational, as opposed to translational, order, have been the subject of a considerable body of recent work. The possibility of the converse situation, translational without orientational order, is also not without interest: plastic crystals have been known for eighty years or more in organic systemis and inorganic ones with complex ligands, but not, to our knowledge, been found in an intermetallic system. This paper will briefly review our recent discoveries of plastic crystal behavior in high-temperature solid phases of the semiconducting alloys $\mathrm{CsPb}(1,2)$ and NaSn (3).

\section{THERMODYNAMICS}

$\mathrm{CsPb}$ and $\mathrm{NaSn}$ belong to a class of Zintl comprunds in which charge transfer and directional bonding leads to the formation of $\mathrm{M}_{4}{ }^{4-}(\mathrm{M}=\mathrm{Pb}$ or $\mathrm{Sn}) \mathrm{Zintl}$ ions in both solid and liquid $(4,5)$. Drop-calorimetric studies in our laboratory have shown that both $\mathrm{CsPb}(6)$ and NaSn (7) exhibit two transitions near the melting point with comparable changes in entropy $\Delta S$ (Fig. 2.). The measured transition temperatures are $T_{1}=596^{\circ} \mathrm{C}, T_{2}=647^{\circ} \mathrm{C}$ for 


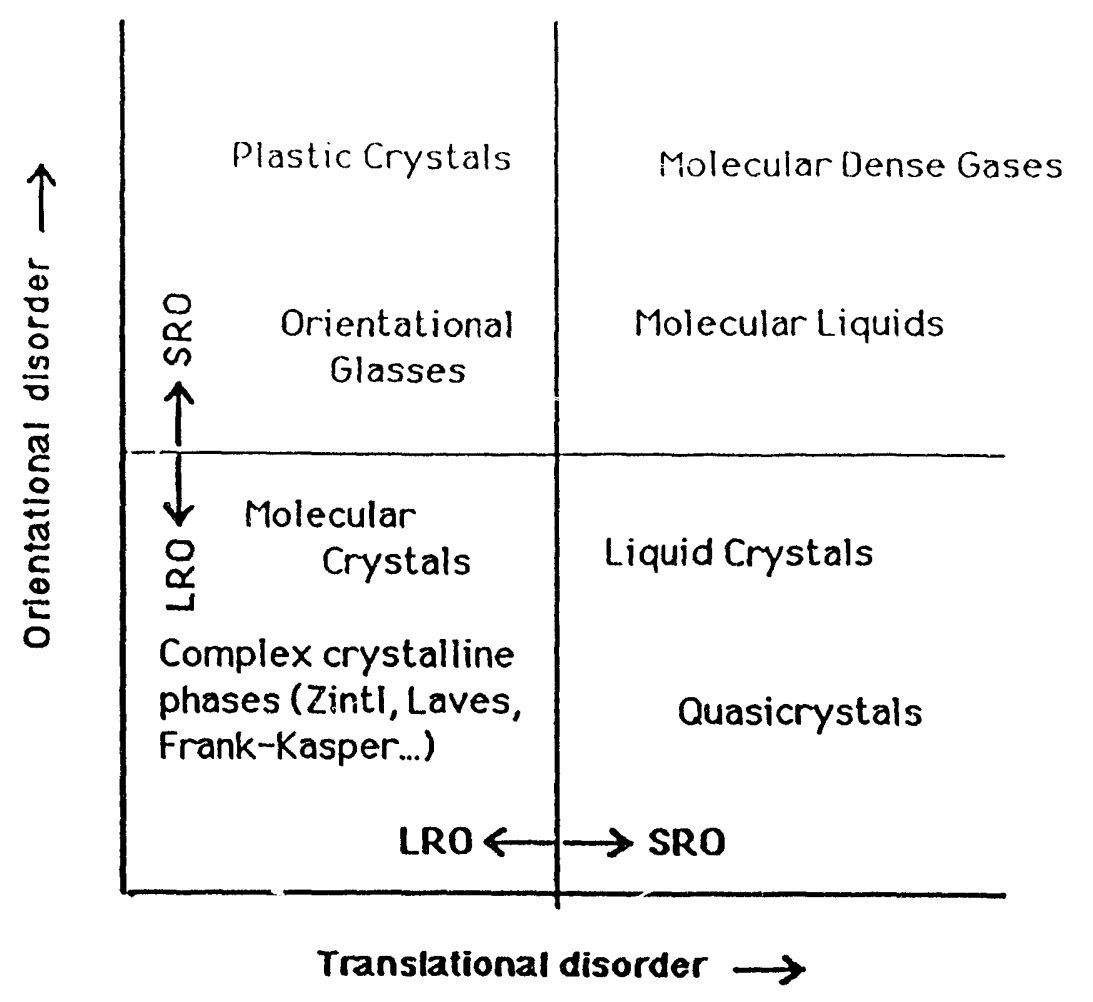

Figure 1. Types of order and disorder in condensed matter

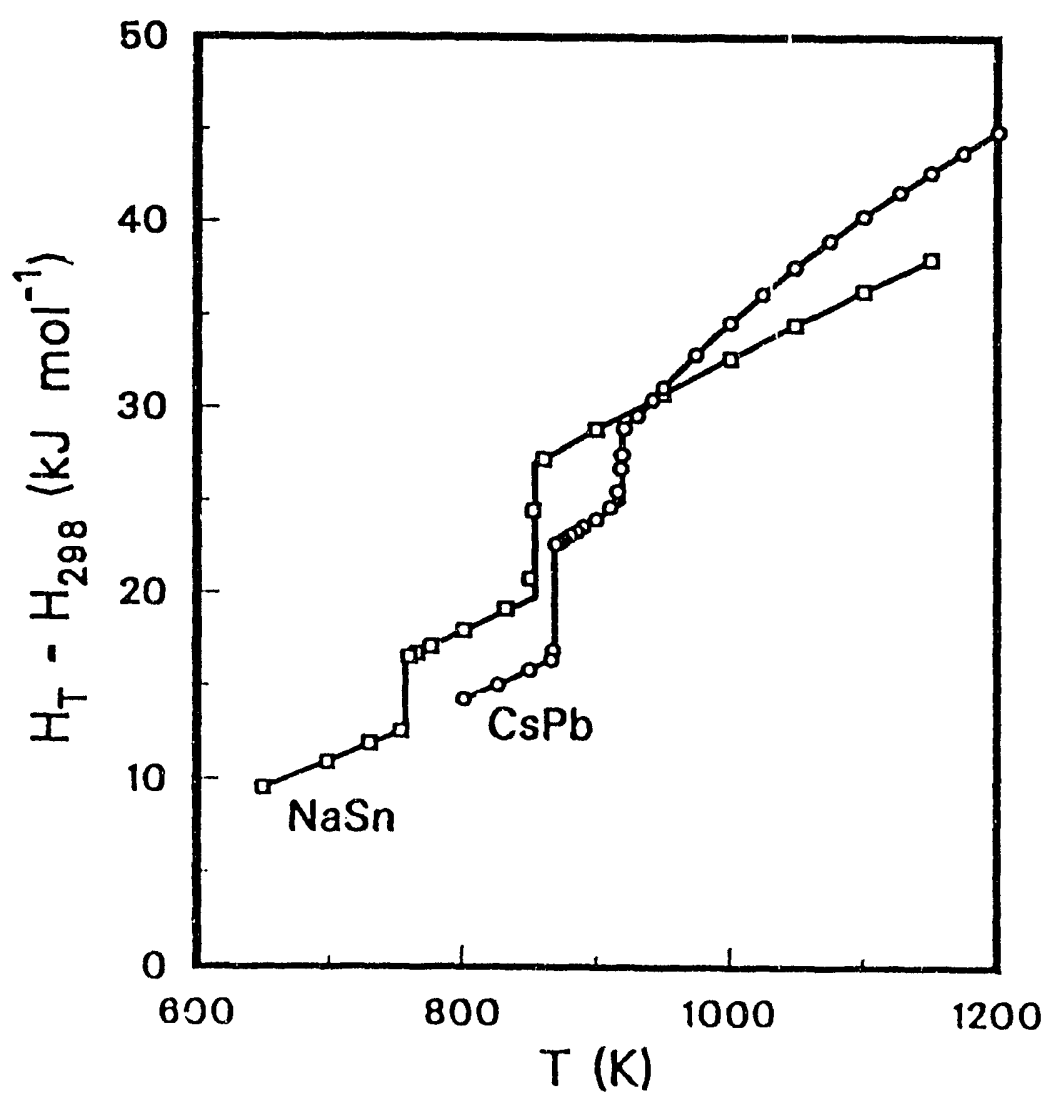

Figure 2. Enthalpy of $\mathrm{NaSn}$ and $\mathrm{CsPb}$ 
$\mathrm{CsPb}$ and $\mathrm{T}_{1}=484^{\circ} \mathrm{C}, \mathrm{T}_{2}=581^{\circ} \mathrm{C}$ for $\mathrm{NaSn}$. The other lead and tin compounds in the same class exhibit only one in the range of temperature investigated, extending about $100^{\circ}$ below the melting point. The phase diagram of $\mathrm{CsPb}(8)$ is inconclusive regarding the existence of more than one phase at the equiatomic composition (Fig.3). The large disagreement in the melting points determined from calorimetry $647^{\circ} \mathrm{C}$ and from liquidus $\left(620^{\circ} \mathrm{C}\right)$ precludes any correlation between the phase diagram and the thermodynamics. On the other hand, in an early study of NaSn (9, Fig. 4), Hume-Rothery identified a phase transition which he characterized simply as a "polymorphic phase transformation in the solid". The temperature $\mathrm{T}_{1}$ of this transition and $\mathrm{T}_{2}$, that of the solid-liquid transition, were $483^{\circ} \mathrm{C}$ and $578^{\circ} \mathrm{C}$ respectively, very close to the values found in the calorimetric measurements (7).
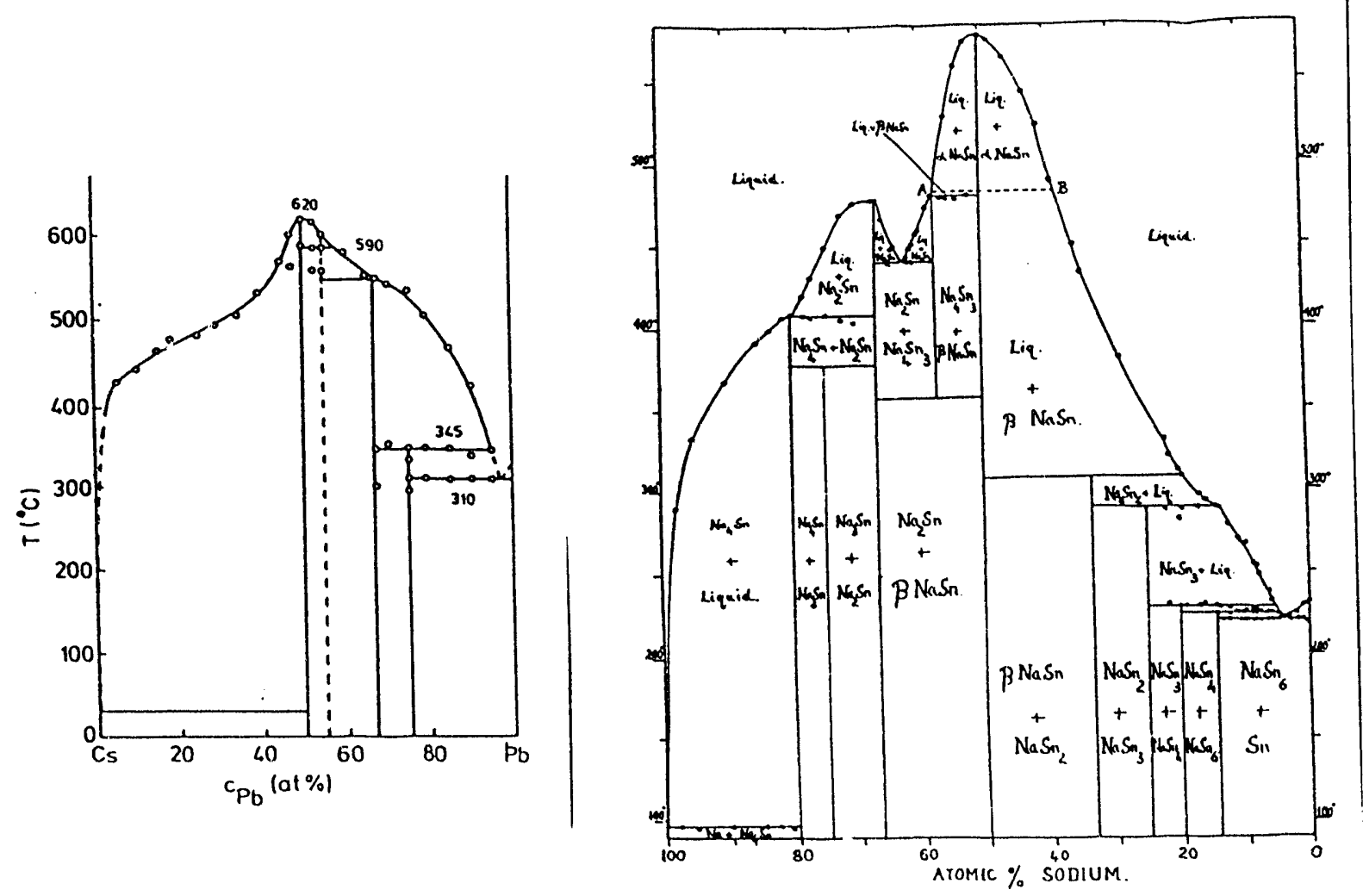

Figure 3. Phase diagram of $\mathrm{Cs}-\mathrm{Pb}$.

Figure 4. Phase diagram of Na-Sn (Hurne-Rothery)

The electrical transport and thermodynamics of NaSn are quite different from those of $\mathrm{CsPb}$. Liquid $\mathrm{CsPb}$ remains in the semiconducting regime while liquid $\mathrm{NaSn}$ becomes semimetallic. The heat capacity of liquid $\mathrm{CsPb}$ in the vicinity of the melting point is extremely large, about 10 times that is expected from additive behavior, while the heat capacity of liquid NaSn is only slightly larger, by about a factor of 2 . 
To resolve the nature of intermediate phase in CSPb, we made neutron diffatetion measurements (4) in all thee phases, which following llume-Rohery we will label $\beta$ $\left(\mathrm{l}<\mathrm{l}_{1}\right), \alpha\left(\mathrm{T}_{1}<\mathrm{T}<\mathrm{T}_{2}\right)$ and $\ell\left(\mathrm{l}_{2}<\mathrm{l}\right)$. The $\beta$ phase revealed a crystalline powder pattern for which Rietveld analysis gave the crystal structure shown in Fig. 5 . It is analogous to that found for $\mathrm{NaPb}$ by Marsh and Schoemaker (10) and shows well defined $\mathrm{Pb}_{4}{ }^{4-}$ tetrahedral Zintl ions enclosed by larger, oppositely directed $\mathrm{Cs}_{4}{ }^{4+}$ tetrahedra, leading to $\mathrm{Cs}_{4} \mathrm{~Pb}_{4}$ structural units. At small $Q, \sim 1 \AA^{-1}$, there is an unresolved double Bragg peak. In the $\alpha$ phase this peak persists but the rest of the diffraction pattern is diffuse, so a crystal structure determination is impossible. In the $\ell$ phase the entire pattern is diffuse, but there is a relatively sharp peak at the wave vector $Q$ of the first Bragg peak in the solid. This peak, a "first sharp diffraction peak" (FSDP), is a signature of large structural units in the liquid, which we have identified with the survival of $\mathrm{Cs}_{4} \mathrm{~Pb}_{4}$ structural units $(4,6)$.

NaSn has a homologous crystal structure (11) and in the liquid phase shows a similar FSDP observed by Alblas et al. (12). No diffraction measurements have been made, to our knowledge, in the $\alpha$, phase.

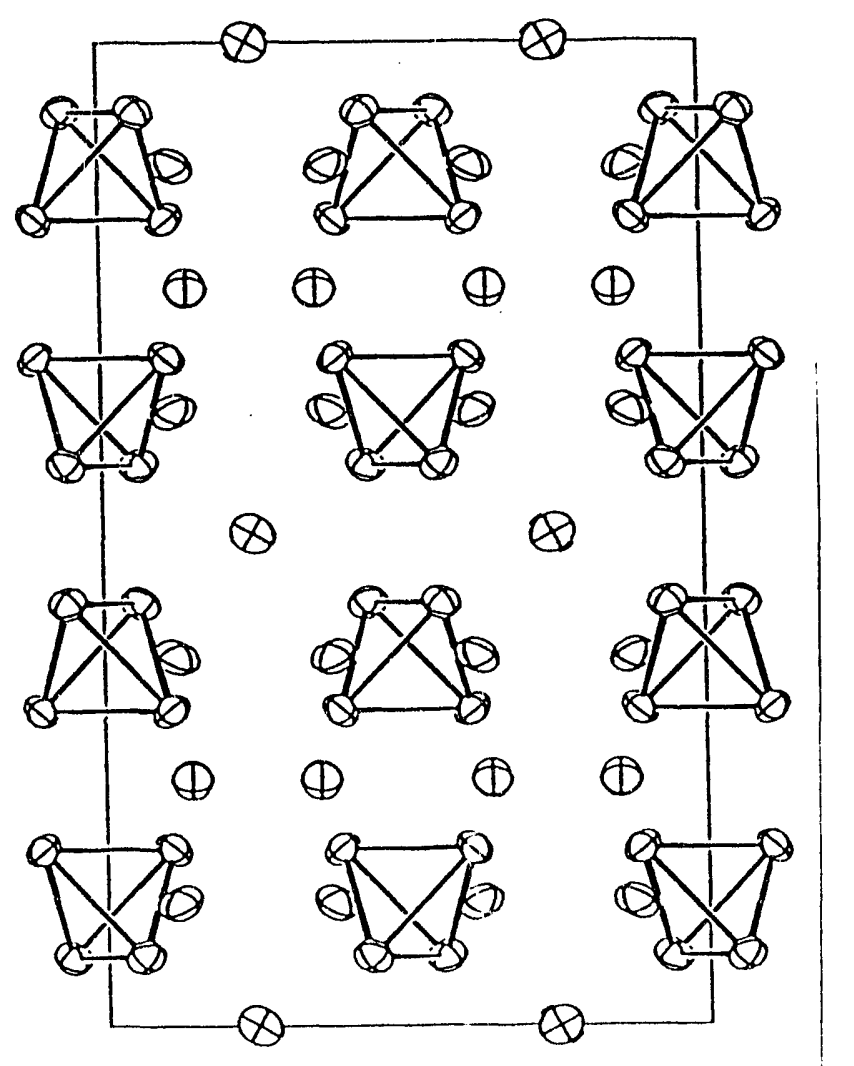

Figiure 5. Crystal structurc of Csl'b

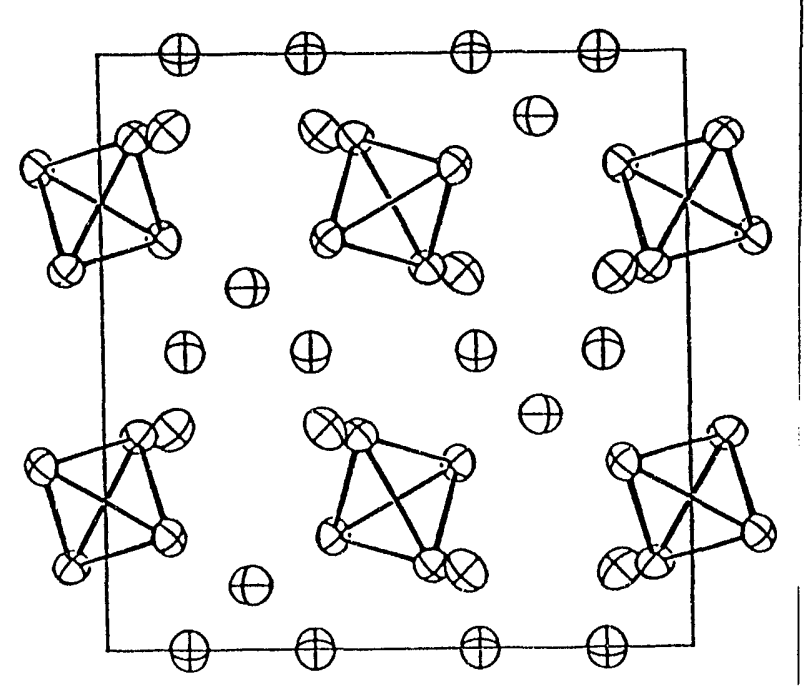

a) Projections onto a ce plane:

b) Projection onto a-b planc. 
The diffuse nature of the diffraction pattern in $\mathrm{CSPb}$ at higher $\mathrm{Q}$ suggest a dynamic disorder. We therefore carried out quasielastic neutron scattering measurements at the Institute Laue Langevin. As expected, the $\beta$ phase showed no energy broadening of the elastic peaks, while the $\ell$ phase showed broadened peaks characteristic of diffusion in the liquid. On the other hand in the $\alpha$ phase the scattering was composed of a combination of elastic and broadened components. The $\mathrm{Q}$ dependence of the elastic and broadened components is shown in Fig. 6, together with the results of a simple model calculation based on random jump reorientations of $\mathrm{Cs}_{4} \mathrm{~Pb}_{4}$ structural units between the four orientations observed in the $\beta$ phase $(1,2)$. The good fit between data and model calculations indicates that the $\alpha$ phase is a plastic crystal characterized by jump reorientations of structural units. The peak in the quasielastic intensity at $Q \sim 0.9 \AA^{-1}$ suggests that the $C$ s atoms are involved in the dynamical process since a large interatomic distance is required to reproduce a peak at
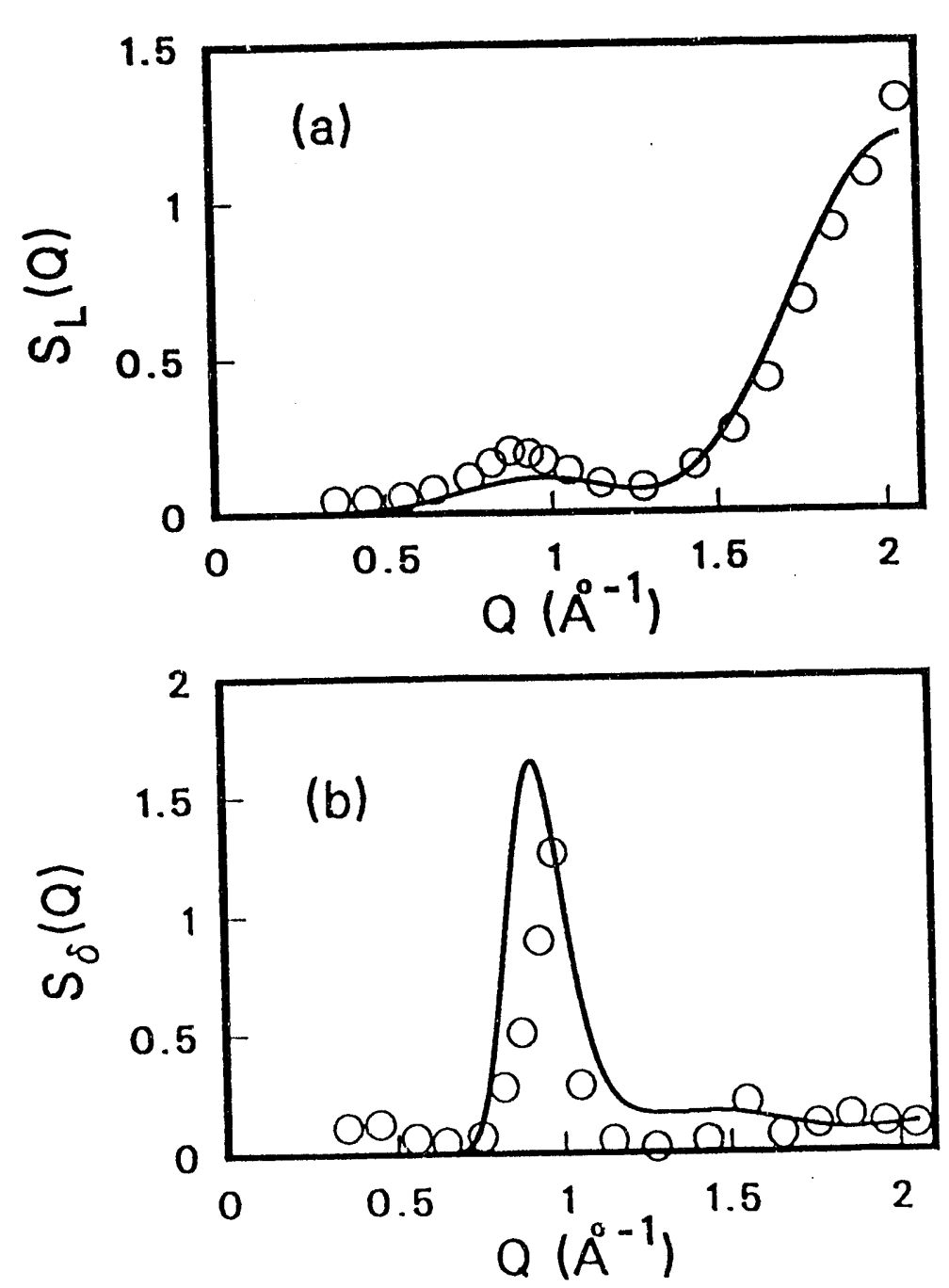

Figure 6. Structurc factors for quasiclastic scattering from $\mathrm{CsPb}$ at $600-630^{\circ} \mathrm{C}$.

(a) Lorentzian (b) $\delta$-function 
this Q. However, the large entropy change at the transition, $\Delta S_{1}=7.15 \mathrm{~J} \mathrm{~mol}^{-1} \mathrm{~K}^{-1}$, suggests that the $\mathrm{CS}$ atoms are not rigidly bound to the $\mathrm{Pb}_{4}^{4-}$ tetrahedra during the reoricntation.

Recent measurements of quasielastic scattering from NaSn at the ISIS pulsed neutron source at Rutherford Appleton Laboratory (U.K.) show a broadened component (3), the intensity of which is given in Fig. 7. In this case the elastic diffuse scattering is close to zero and varies randomly with $Q$. This situation is similar to that observed in the iugh-temperature phase of $\mathrm{C}_{60}$ where quasielastic broadening is explained on the basis of rotational diffusion (13). This is quite feasible for a relatively isotropic molecule like $\mathrm{C}_{60}$ but somewhat unexpected for a structural unit of tetrahedral symmetry which is found in NaSn, at least in the $\beta$ phase. Examination of the different possible diffusion mechanisms (i.e. rotational diffusion, hindered rotation or jump reorientation) is underway.

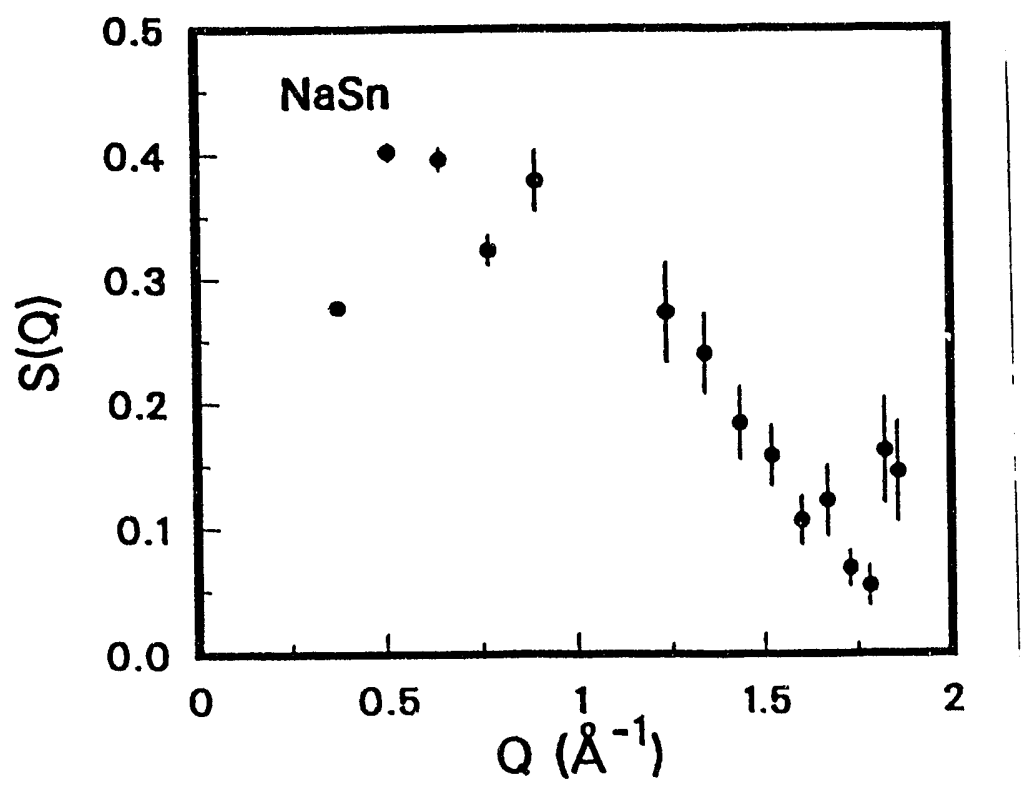

Figure 7. Structure factor for quasielastic scattering from $\mathrm{NaSn}$ at $500^{\circ} \mathrm{C}$.

\section{CONCLUSIONS}

Plastic crystal behavior is observed in $\mathrm{CsPb}$ and $\mathrm{NaSn}$ at high temperature. This behavior is associated with $\mathrm{M}_{4}{ }^{4-}$ or $\mathrm{A}_{4} \mathrm{M}_{4}$ structural units $(\mathrm{A}=\mathrm{Cs}$ or $\mathrm{Na}, \mathrm{M}=\mathrm{Pb}$ or $\mathrm{Sn}$ ) orientationally disordering at a temperature $T_{1}$, about $50^{\circ} \mathrm{C}$ below the melting point $T_{2}$ where trans'ational disorder sets in. The nature of the orientational disorder appears to be different in the two phases, exhibiting jump reorientations in $\mathrm{CsPb}$ and a more isotropic behavior in $\mathrm{NaSn}$. In other Zintl compounds such as $\mathrm{KPb}$, there is a single melting point where orientational and translational disorder sets in simultaneously. The classification of the 
different Zintl compounds into these two different kinds of behavior will require detailed calorimetric measurements over an extended range below the melting point, or alternatively neutron diffraction or quasielastic scattering measurements just below it.

\section{ACKNOWLEDGEMENTS}

This work was performed under the of the U. S. Department of Energy, Division of Basic Energy Sciences, Materials Sciences, Contract No. W31-109-ENG-38.

\section{REFERENCES}

1. D.L. Price, M.-L. Saboungi, R. Reijers, D. Kearley, and R. White, Phys. Rev. Lett. 66, 1894 (1991).

2. D.L. Price and M.-L. Saboungi, Phys. Rev. 44, 7289 (1991).

3. M.-L. Saboungi, D.L. Price, and W.S. Howells, to be published.

4. H.T.J. Reijers, M.-L. Saboungi, D.L. Price, J.W.Richardson, J.K.Volin, and W. van der Lugt, Phys. Rev. B 40, 6018 (1989).

5. H.T.J. Reijers, M.-L. Saboungi, D.L. Price, and W. van der Lugt, Phys. Rev. B41, 5661 (1990).

6. M.-L. Saboungi, H.T.J. Reijers, M. Blander, and G.K. Johnson, J. Chem. Phys. 89, 5869 (1988).

7. G.K. Johnson and M.-L. Saboungi, to be published.

8. J.A. Meijer, W. van der Lugt, and G.J.B. Vinke, J. Phys. F 16, 845 (1986).

9. W. Hume-Rothery, J. Chem. Soc. 131, 947 (1928).

10. R.E. Marsh and D.P. Shoemaker, Acta Crystallogr. ó, 196 (1953).

11. W. Mueller and K. Volk, Z. Naturforsch. 32b, 709 (1977).

12. B.P. Alblas, W. van der Lugt, J. Dijkstra, W. Geertsma, and C. van Dijk, J. Phys. F 13, 2465 (1983).

13. D.A. Neumann, J.R.D. Copley, R.L. Cappelletti, W.A. Kamitakahara, R.M. Lindstrom, K.M. Creegan, D.M. Cox, W.J. Romanow, N. Coustel, J.P. McCauley Jr., N.C. Maliszewsky, J.E.Fischer, A.B. Smith III, Phys. Rev. Lett. 67,3808 (1991). 

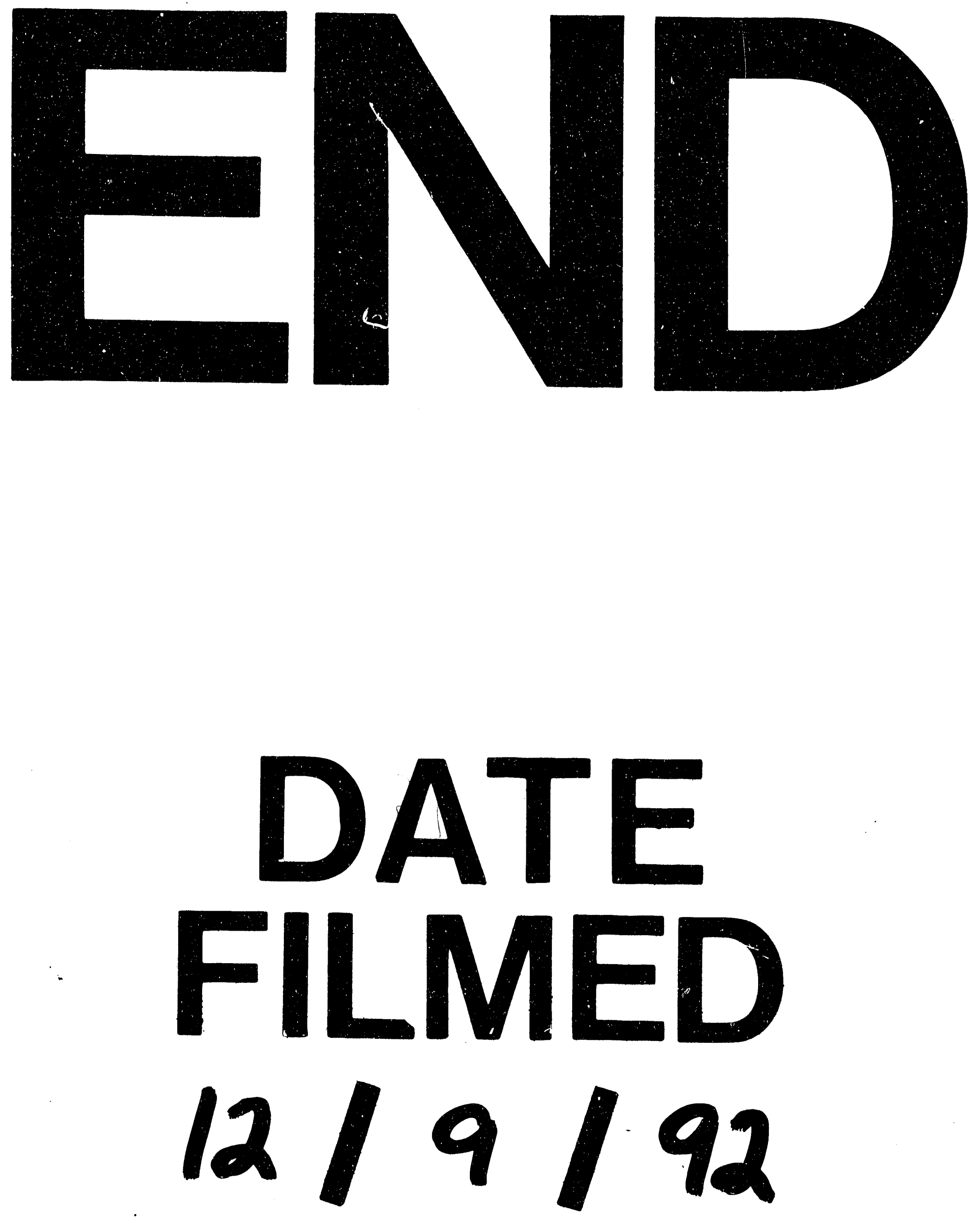
